\title{
Analysis of Flower Border Design and Maintenance in the Later Period
}

\author{
Beijing Botanical Garden, Beijing, 100000, China Walyhs@sohu.com
}

\section{Importance of flower border design}

In contemporary society, mixed flower border has been more widely used, which has a very distinctive feature, that is, it contains rich species of plants. At the same time, different plants have different flowering seasons, and plants bloom one after another as seasons change, leading to a kind of different beauty ${ }^{[1-3]}$. And the appreciation period of many foliage plants is relatively long, so mixed flower border has a very strong ornamental value. Perennial root flowers play a very important role in the use of mixed flower border. In most cases, appreciation of flower border of perennial root flowers can be maintained for three to five years after planting, and the cost of replacing annual and biennial herbs and flowers can be saved. Therefore, flower border design is a very important job, and a good flower border design can make the environment more beautiful, so that people's mind can be sublimated. ${ }^{[4]}$

\section{Principles of selection of flower border plants}

The selection of flower border plants is not arbitrary but determined by scientific and rational analysis and discussion. The relevant designers shall fully consider all aspects and make design of flower border more perfect. In general, principles of selection of flower border plants include the following aspects.

1) It's best for flower border plants to live through the winter and it's best for them to be perennial flowers. When selecting the variety, the selection of annual and biennial flowers shall be minimized, because the constitution of perennial flowers will be better, so that they can be more adapted to the local climate change, which is a great advantage for living through the winter in the open field. For example, in Beijing, the northern China, phalaris arundinacea, Chinese Pennisetum, oat grass, etc. can live through the winter in the open field. ${ }^{[5]}$

2) The selected flower border plants need to have strong resistance to stress, management of this part of plants shall be relatively extensive, and it's easy for them to survive. If plants have relatively high requirements for the environment, it will bring workers a lot of work, which sometimes can cause the death of plants due to insufficient care and eventually lead to the destruction of flower border.

3) Blooming period of the selected flower border plants shall be relatively long, and once long blooming period is ensured, ornamental value for a long time can be ensured. At the same time, the appreciation value of plants should be relatively high, and plants should not be the same green shrubs without flowers.

3. Basic principles of configuration of flower border plants

1) The configuration of flower border plants needs to follow the relevant principles. First, a

\begin{abstract}
Since the $21^{\text {st }}$ century, China's economy has enjoyed rapid development and people's living standards have been improved. At the same time, the pursuit of beauty of people is getting increasingly higher and landscaping of and design of gardens has been widely pursued by people. This paper has discussed and analyzed the design of flower border and maintenance of flower border in the later period, hoping to provide some help and support for the relevant technical workers.
\end{abstract}

Key words: Flower border design; maintenance in the later period; analysis

Published online: 31st January, 2018

single plant shall not be cultivated. Instead, three to five plants shall be organized into a clump. These clumps shall then be freely combined to achieve a beautiful design. ${ }^{[6]}$

2) Each clump shall be connected, and the smoothness of connection and harmony of transition shall be ensured. After the connection is completed, overall unity shall be checked to see if each clump supports each other and the integrity shall be guaranteed.

3 ) In terms of configuration of flower border plants, we not only need to ensure that the flowers can be appreciated, but also pay attention to leaves and whole plants outside flowers, and the collective beauty shall 
be guaranteed as much as possible.

4) Selection of plants in the flower border shall be scientifically and rationally analyzed. Growth of plants shall be relatively easy and needs no special care. Plants around the plant shall be able to extend to the plant when it blooms or after its death, and branches or leaves of other plants shall be able to cover the ground.

5) Pay special attention to background design. Background design is a very important task. Through background design, we can make the background of the entire flower border neat and uniform with a kind of overall continuous and lasting beauty. In a specific operation and design, a plant can be used as the background so as to make the background harmonious as a whole. At the same time, we need to pay attention to the selection of foreground plants. Since the background plants belong to a single species, foreground plants shall be of varieties, thus diversifying the foreground and avoiding the recurrence of the same species of plants, so that blooming period can be uninterrupted. ${ }^{\text {[7] }}$

6) When people appreciate the flower border, they will first see plants at the forefront. Therefore, flower border plants at the forefront shall be low and short plants, such as zephyranthes candida, Chinese herbaceous peony, dahlia, annual phlox, iris and other plants. In addition, the length of the flower border design shall be carefully considered according to the actual needs. In general, we can use the flower border design between 10 to 100 meters. After the flower border is fully arranged, it shall be trimmed on a regular basis. Flower border is trimmed every three to five years generally.

\section{Arrangement occasions of the flower border}

Flower border arrangement is a relatively complex job, and design concept of designers affects the style of flower border arrangement to a large extent. Therefore, we shall continue to learn, constantly update the concept of knowledge and sum up the experience in the specific work and practices, so that the flower arrangement border can be more scientific and rational.

1) For the belt space between the building and roads, we can arrange the flower border as the basic decoration to enhance the beauty of the entire building. The contrast between the building and ground will be relatively strong. By arranging flowers and trees, we will alleviate this kind of contrast to a certain extent. In fact, the flower border can soften hard corners of the regular building to some extent, so that the building becomes softer and is able to be integrated into the surrounding background. Through scientific and rational design, flower border can effectively increase the beauty of the curve and color of the environment, highlight the theme and make people pleasant. It shall be noted that when the building is too tall, we shall not use the flower border to decorate, because the ratio between the two is too large, and this effect is not very good. The flower border planted as the foundation of the building shall be the one-sided flower border that can be appreciated.

2) When arranging the flower border on the road, we shall take all-sided factors into account. In actual work, plants are planted in a natural way so that they can produce very rich colors and layers And with the careful arrangement of workers, it will ultimately take on an effect pleasant to the eye. When tourists are exposed to such an environment, their hearts will be filled with an inexplicable feeling of relaxation, effectively reducing the pressure in the heart and making people happy in body and soul. In general, flower border is mainly arranged in the following three ways: first, it can be arranged right in the middle of the road. Since it is at the very center, both sides need to be taken into account and two-sided flower border can be arranged for appreciation. At the same time, both sides of the road shall be properly arranged to match with the flower border, and some simple grasslands or trees can be planted. Second, a row of onesided flower borders on the one side of the road can be arranged for appreciation, which is facing one side of the road. Therefore, flower border design shall focus on integrity and unite with surrounding environments to form a whole composition. Finally, a row of two-sided flower borders for appreciation in the middle of the road, and one-sided flower border can be arranged on both sides of the road respectively. This method of arrangement will use a lot of materials and money, and accordingly, the effect of this method of arrangement is also the best, which will greatly change the environment, effectively increase green area and improve the quality of life.

3) In retaining walls, toilets and other places, shielding materials shall be set up reasonably. In this case, the flower border can be set up in front of shielding materials to beautify these areas. As for fences in the courtyard and the relevant retaining walls, it can be seen that their facades are relatively simple, so we can plant some lianas here. In addition, the one-sided flower border for appreciation can be arranged in front of the wall which can be well utilized as background the flower border.

4) The flower border has extremely important applications in parks. In terms of the flower border on the roadside, it's usually set up on one side or both sides of the road, so that the road can have a higher ornamental value and tourists can appreciate it while walking. As for the flower border in the woods, it's often located on the edge of the woods with shrubs as the background and short and small grass as the foreground to create a kind of 
beauty with layers. ${ }^{[8]}$

\section{Analysis of flower border maintenance in the later period}

When the flower border is arranged, we also need to carry out regular maintenance work to ensure that the flower border can always be kept in perfect condition. In fact, maintenance is relatively complex. Workers shall carefully observe details of the flower border, timely find and solve problems. Maintenance of the flower border is very important. In the process of maintenance, workers need to weed, water, apply fertilizers and trim, etc. Rainwater is abundant in regions south of the Yangtze River with a run of wet weather frequently. Therefore, when the flower border is arranged, you need to pay special attention to the waterabsorbing conditions of flower border plants. If plants are often soaked in water, they will overproduce and be weak, and if serious, it will even cause problems, such as lodging and rotting roots, resulting in irreparable losses. To solve this problem, we shall pay attention to weather in time. At the same time, the detailed watering and drainage plans shall be developed according to the actual situation of the plant to strictly ensure that the water absorption of the plant is within a reasonable range. Another example is that, in the northern area, due to its distinctive seasonal characteristics, that is, in the winter, evergreen plants and branch plants for appreciation mainly support its landscape, such as procumbent juniper, holly leaves and flowering shrubs with branches and other evergreen plants, which can create a poetic and pictorial flower border with winter features in the northern area. Therefore, in order to ensure the persistence of the flower border landscape and realize scattered flowering of the plants, the plants can be classified under the guidance of the flowering season, and then they can be reasonably configured after comprehensively considering such plant ecological characteristics as color, plant profile and height, to provide a guarantee for the ornamental value of the flower border landscape.

Most of the tall flowering perennial root plants have a little need for fertilizer, so the workers should reasonably control the fertilizer amount used for the plants, to prevent the overfertilization; in case of excessive use of fertilizer, the plants may have overnutrition and fewer flowers, besides, this can also bring in other adverse effects on the plants. Such as plantain lily, bletilla striata and hydrangea, they are the half-shade plants among the ornamental plants. If the fertilizer amount used for them is not reasonable, their growth will be unhealthy and they may even suffer diseases and pests. The fertilizer amount used for those foliage plants should be increased properly, because these plants have a higher requirement for the soil fertility. If the soil fertility is insufficient, their growth will be severely limited, which may causeing unhealthy growth, and they are easy to die under the blazing sun in summer. Take lysimachia nummularia aurea as an example, though these plants like light, they can resist halfshade but cannot be under the sunlight for a long time; they can be easy to get southern blight under the effect of exposing to the sunlight, or the branches and leaves may die.

Pruning is an essential link in themaintenance work for the flower border, and pruning can be divided into the following categories in most cases.

The first one is re-pruning after flowering, and this is a basic pruning method and widely applied in the maintenance of flower border. Generally, this method is mainly used for the high flowering perennial root plants, such as coreopsis basalis and large-flower leucanthemum vulgare; the former should be re- pruned in time after flowering to reduce its height and prevent lodging, besides, this can facilitate it to grow out new branch bud; the upper flowering part of the latter should be also pruned after flowering and this is of great significance; the whole old branch above the ground can be removed when the new lower leaves grow out.

The second one is the shaping and pruning. As the name suggests, this method is mainly used to shape the overall shape of the flower border, to make it more beautiful. This kind of pruning method is mainly used for evergreen shrubs, such as teucrium fruitcans and French lavender, and the pruning time should be controlled reasonably and they are generally pruned after flowering. Shaping and pruning can facilitate the growth of these plants and then they will become more plump.

The last one is the pruning in winter and spring. As most plants will become withered and yellow when the winter is coming, the flower border will be no longer so beautiful. To solve this problem, we need to prune the withered and yellow branches above the ground to make it tidier. The pruning time should be particularly noted for those higher ornamental grasses; they can be pruned in spring before the new buds grow out, to ensure the working effect with the consideration of the landscape effect of the plants.

The root system of perennial root plants will become more and more intensive after years of growth and this intensiveness can cause a series of problems, for example, difficult absorption of nutrition. If the plants cannot absorb nutrition for a long time, their root system will become very fragile and this can even cause the plants' death under serious conditions. To solve this problem, the related workers should strengthen the observation, timely dig out the perennial root plants and then conduct ramet to efficiently decrease the intensiveness of the root system. 
Meanwhile, a proper amount of organic fertilizer can be used in the soil, to increase the fertility and ensure the nutrition absorption of the plants.

All in all, flower border design and late maintenance are very important. The related workers must reinforce learning and sum up experience in their specific work practice, so that they can complete the work of flower border design and maintenance better.

\section{References:}

[1] Huajuan Yin. Flower Border Design for Public Green Space[J]. Modern Horticulture, 2015(16):8788. (in Chinese)

[2] Qi Wei. Application of Flower Border Landscape in Road Landscape Design--Take Jinxiu Road of Shanghai as an example[J]. Chinese Horticulture Abstracts, 2013(11):100-101,184. (in Chinese)

[3] Zhuo Guo. Flower Border Types and Design Essentials[J]. Chinese

Horticulture Abstracts, 2011(01):106-109. (in Chinese)

[4] Chunyang Gao. Application of Flower Border Plants in Urban Landscaping[J]. Architectural Engineering Technology and Design, 2015(28). (in Chinese)

[5] Xinran Wu, Jingjing Wang. Discussion of Flower Border Design in Garden Landscape[J]. China Venture Capital, 2013(A32):403-403. (in Chinese)

[6] Zhiping Deng, Junjie Guan, Xueliang Guan. Brief Analysis of Flower Border Design[J]. Agricultural Science-technology and Information: Modern Landscape Architecture, 2011(4):20-22. (in Chinese) [7] Songya Luo. Application of and Discussion of Flower Border in Courtyard Design[J]. Da Guan, 2017(2). (in Chinese)

[8] Linyun Wang. Discussion of Design and Application of Flower Border in Urban Landscapes[J]. Di Tan Di Chan, 2016,2(19). (in Chinese) 